\title{
A Combination of Direct Viable Counting, Fluorescence in situ Hybridization, and Green Fluorescent Protein Gene Expression for Estimating Plasmid Transfer at the Single Cell Level
}

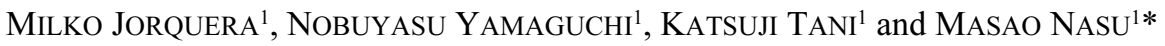 \\ ${ }^{1}$ Graduate School of Pharmaceutical Sciences, Osaka University, 1-6, Yamada-Oka, Suita, Osaka 565-0871, \\ Japan
}

(Received December 5, 2005-Accepted February 11, 2006)

\begin{abstract}
Plasmid-mediated conjugation is an important mechanism through which bacteria establish new genetic traits in the environment. Here we used a combination of direct viable counting (DVC), fluorescence in situ hybridization (FISH), and green fluorescent protein (GFP) gene expression to estimate plasmid transfer frequencies (TFs) on nutrient-limited media at the single cell level. Conjugation experiments on nutrient-rich and -limited media were carried out using Pseudomonas fluorescens as a donor of a broad-host-range plasmid (RK2) tagged with the GFP gene and P. putida as the recipient. FISH-GFP and DVC-FISH-GFP allowed for the accurate detection of donor, recipient and transconjugants by fluorescence microscopy. The TFs obtained by these culture-independent approaches were 1 to more than 3 orders of magnitude higher than those determined by selective plate-counting. Lower and variable TFs obtained by selective plate-counting emphasize the importance of culture-independent approaches in plasmid transfer studies. The application of DVC before FISH-GFP on nutrient-limited medium produced elongated and/or fattened cells and resulted in a better fluorescence signal in target bacteria cells and better accumulation, maturation and fluorescence-emission of GFP within transconjugant cells, facilitating the detection and identification of cells compared with FISH-GFP alone. The DVC-FISH-GFP could be useful for other conjugation studies using bacteria with low metabolic activity under oligotrophic/stressful conditions or studies which require a precise determination of plasmid transfer events during short-term conjugation experiments.
\end{abstract}

Key words: direct viable counting, green fluorescent protein, fluorescence in situ hybridization, plasmid transfer, Pseudomonas

Plasmid transfer by conjugation is an important mechanism by which bacteria establish new genetic traits that allow for rapid adaptation to changing environments ${ }^{23,47,51)}$. Broad-host range plasmids (incompatibility groups IncP, $\mathrm{W}, \mathrm{N}$ or $\mathrm{C}$ ) are of particular interest because they can be transferred and stably maintained in a wide range of bacteria $^{22)}$. The transfer of self-transmissible and mobilizable plasmids among bacteria in diverse terrestrial and aquatic habitats has been studied ${ }^{14)}$. Pseudomonas spp. are among the most widely used microorganisms in plasmid transfer studies because they can function in a pathogenic,

\footnotetext{
* Corresponding author; E-mail: nasu@phs.osaka-u.ac.jp, Tel: +816-6879-8170, Fax: +81-6-6879-8174
}

plant-colonizing, or xenobiotic-degrading context and are ubiquitous in various environments including soil, fresh water, sediment, sea water, hospitals and natural biofilms $^{18,32,48,49)}$.

Studies on plasmid transfer have shown that nutrient availability and the physiological state of the mating partner affect plasmid transfer frequencies ${ }^{11,14,52)}$. The influence of starvation and oligotrophic conditions on plasmid transfer has been addressed using culture-dependent methods ${ }^{21)}$. Plasmid transfer during mating in nutrient-rich broth is undetectable when Escherichia coli cells (donor) are starved for $24 \mathrm{~h}$ beforehand in river water ${ }^{35)}$. In contrast, the ability of $E$. coli cells starved (recipient) before mating under the same conditions, to receive and express plasmid-encoded 
genes, does not vary ${ }^{5)}$. In seawater, plasmid transfer between marine Vibrio spp. is below the detectable limit when donors and recipients are starved for more than 14 days before mating ${ }^{20)}$. Using a culture-independent approach, Dahlberg et al. ${ }^{10)}$ transferred GFP-tagged plasmids from starved $P$. putida to different phylogenetically recipient cells (including bacteria indigenous to seawater) in artificial and natural seawater without adding nutrients.

Methods used to investigate plasmid-mediated conjugation can be classified into two major types depending upon whether or not they are based on bacterial cultivation. The major limitation of culture-dependent methods is that in natural habitats only a minority of the bacteria present can be cultured by conventional methods ${ }^{2}$. In addition, whether all transconjugants can grow on selective media is unclear, rendering identification difficult and erroneous. Molecular techniques have recently been added to conventional selective plate-counting methods for studies of conjugal plasmid transfer $^{52)}$. Green fluorescent protein (GFP), isolated from the jellyfish Aequorea victoria, is a valuable tool for examining biological phenomena because cells can be studied in the absence of exogenous substrate or energy ${ }^{17}$. A GFPbased method can detect single cells, thus allowing in situ monitoring of plasmid transfer without transconjugant cultivation. However, transconjugant cells showed a high degree of variation in the level of GFP they expressed, implying that cells with high levels of GFP fluorescence harbor the plasmid for a longer period of time than those showing low levels of fluorescence (and consequently received the plasmid more recently ${ }^{19}$. Moreover, studies using a GFP marker for environmental applications have showed extensive variability in the expression of GFP in different bacterial species and that the intensity of GFP fluorescence increases over time, but the influence of environmental conditions on GFP expression is unknown ${ }^{17)}$.

Fluorescence in situ hybridization (FISH) is used for the simultaneous visualization, detection, identification, enumeration and localization of phylogenetically targeted bacteria at the species, genus and family levels ${ }^{34)}$. FISH has been combined with GFP gene expression to specifically detect transconjugants during conjugation in biofilms ${ }^{23,43)}$, flow chamber ${ }^{8)}$ and activated sludge ${ }^{19}$. Direct viable counting (DVC), commonly used when counting viable but nonculturable (VBNC) bacterial cells, has also been combined with FISH to improve the detection and enumeration of VBNC bacteria in aquatic environments ${ }^{24,25,37)}$. The DVC method is based on the incubation of samples in the presence of nutrients and a single antimicrobial inhibitor of DNA-gyrase. The inhibitor prevents cell division without affecting other metabolic activities allowing cells to continue to metabolize nutrients and become elongated and/or fattened after incubation ${ }^{27,53)}$.

In this study, DVC was combined with FISH and GFP gene expression to improve the sensitivity of the FISH method by increasing intracellular rRNA levels within target cells and provide more time for the accumulation, maturation, and expression of GFP within transconjugant cells in conjugation studies on nutrient-limited media. P. fluorescens was used as the donor of a derivative broad-hostrange plasmid RK2 (IncP-1 $\alpha$ plasmid), tagged with a GFP gene by transposition, and the $P$. putida recipient was visualized by FISH with a specific Cy3-labeled probe. Plasmid transfer frequencies were estimated by fluorescence microscopy and compared with results of plate-counting on selective media.

\section{Materials and Methods}

\section{Bacterial strains, plasmids and growth conditions}

Table 1 lists the bacterial strains and plasmids used in the present study. All E. coli strains were cultured at $37^{\circ} \mathrm{C}$ on Luria Bertani (LB) agar (10 g tryptone, 5 g yeast extract, $5 \mathrm{~g}$ $\mathrm{NaCl}$ and $15 \mathrm{~g}$ agar per liter of distilled water) and $\mathrm{LB}$ broth, containing the appropriate antibiotic (if required). Pseudomonas strains were cultured in LB broth and on LB agar at $30^{\circ} \mathrm{C}$. The GFP gene was inserted into the RK2 plasmid using the transposon delivery vector pBSL2991), comprising a mini-Tn5 transposon and streptomycin resistance gene. This vector was chosen because in mini-Tn5 transposon family vectors, the DNA fragment is transferred without transposition functions. This feature prevents secondary transposition within bacterial cells and stable DNA insertion $^{12,13)}$. The strain used for maintenance of the pirdependent recombinant plasmids (pBSL299 and its derivatives) was $E$. coli MA9. Rifampicin-resistant $E$. coli was isolated as spontaneous mutants on LB plates supplemented with $150 \mu \mathrm{g} / \mathrm{ml}$ of this antibiotic.

\section{Construction of a broad-host-range plasmid tagged with the GFP gene}

The GFP-tagged derivative of RK2 was constructed essentially as described by Christensen et al. ${ }^{8)}$ for tagging the plasmid TOL with a GFP gene. A synthetic GFP gene (pGFPuv), which emits signal at 18-fold the fluorescence intensity of the wildtype ${ }^{9)}$, was obtained from the vector pGFPuv and cloned downstream of the promoter/operator element ( $\mathrm{P}_{\mathrm{T} 5 / a c}$; comprising the phage $\mathrm{T} 5$ promoter and two

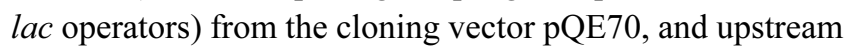


Table 1. Characteristics of bacterial strains and plasmids used in this study

\begin{tabular}{|c|c|c|}
\hline Bacterial strain or plasmid & Description & Source or reference \\
\hline \multicolumn{3}{|l|}{ Bacteria } \\
\hline E. coli MA9 & 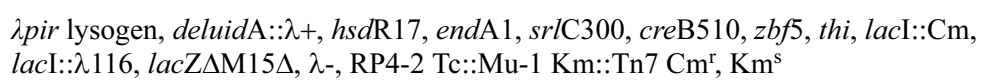 & NCCB 2877 \\
\hline E. coli $\mathrm{C} 600$ & $\mathrm{~F}-, \sup \mathrm{E} 44, l a c \mathrm{Y} 1, t h r-1, l e u \mathrm{~B} 6$, mcrA, thi-1, rfbD $1, f h u \mathrm{~A} 21, \lambda-$ & ATCC 23724 \\
\hline E. coli $\mathrm{W} 3110$ & F-, IN(rrnD-rrnE) $1, \lambda-$ & ATCC 27325 \\
\hline P. putida & Biotype A bacteriophage host, degrades aromatic acids, $\mathrm{Ap}^{\mathrm{r}}, \mathrm{Cm}^{\mathrm{r}}, \mathrm{Sm}^{\mathrm{s}}, \mathrm{Km}^{\mathrm{s}}$ & ATCC 12633 \\
\hline P. fluorescens & $\mathrm{Ap}^{\mathrm{r}}, \mathrm{Sm}^{\mathrm{s}}, \mathrm{Km}^{\mathrm{s}}$ & RIMD 1615005 \\
\hline P. fluorescens & $\mathrm{Ap}^{\mathrm{r}}, \mathrm{Sm}^{\mathrm{s}}, \mathrm{Km}^{\mathrm{s}}$ & ATCC 13525 \\
\hline \multicolumn{3}{|l|}{ Plasmids } \\
\hline pGFPuv & GFPuv gene vector, $A p^{r}$ & Clontech, Inc. \\
\hline pQE70 & Expression vector, $\mathrm{Ap}^{\mathrm{r}}$ & Qiagen, Inc. \\
\hline pBSL299 & Mini-Tn5 transposon delivery vector $\mathrm{Ap}^{\mathrm{r}}, \mathrm{Sm}^{\mathrm{r}}$ & NCCB 3383 \\
\hline RK2 & Self-transmissible $60-\mathrm{Kbp}$ broad-host-range plasmid $\mathrm{Ap}^{\mathrm{r}}, \mathrm{Km}^{\mathrm{r}}, \mathrm{Tc}^{\mathrm{r}}$ & ATCC 37125 \\
\hline pQE70::gfp & $\begin{array}{l}\text { SphI-HindIII GFPuv gene fragment cloned downstream of } \mathrm{P}_{\mathrm{T} 5 / l a c} \text { and upstream of } \\
\mathrm{T}_{\text {to/T1 } 1} \mathrm{Ap}^{\mathrm{r}}\end{array}$ & This study \\
\hline pBSL299::gfp & $\begin{array}{l}\text { NotI fragment } \mathrm{P}_{\mathrm{T} 5 / l a c}:: G F P u v:: \mathrm{T}_{t o / \mathrm{T} 1} \text { from } \mathrm{pQE} 70:: g f p \text { cloned into } \mathrm{pBSL} 299 \text { vector } \\
\mathrm{Ap}^{\mathrm{r}}, \mathrm{Sm}^{\mathrm{r}}\end{array}$ & This study \\
\hline $\mathrm{RK} 2:: g f p$ & $\begin{array}{l}\text { Self-transmissible broad-host-range plasmid, } \mathrm{P}_{\mathrm{T} 5 / l a c}:: \mathrm{GFPuv}:: \mathrm{T}_{\text {to/T1 }} \text { from } \\
\text { pBSL299::gfp inserted at random into RK2 plasmid } \mathrm{Ap}^{\mathrm{r}}, \mathrm{Km}^{\mathrm{r}}, \mathrm{Tc}^{\mathrm{r}}, \mathrm{Sm}^{\mathrm{r}}\end{array}$ & This study \\
\hline
\end{tabular}

NCCB: The Netherlands Culture Collection of Bacteria; ATCC: American Type Culture Collection; RIMD: Research Institute for Microbial Diseases, Osaka University, Japan.

of a region with two strong transcriptional terminators $\left(\mathrm{T}_{t o / \mathrm{T} 1} ; t_{o}\right.$ from phage lambda and $\mathrm{T} 1$ from the $r r n \mathrm{~B}$ operon of E. coli). pQE70 harboring the GFP fragment (designated pQE70::gfp) was prepared by alkaline lysis using E. coli JM109 as the host. The fragment containing $\mathrm{P}_{\mathrm{T} 5 / \text { lac }}$, a synthetic ribosomal binding site (RBSII), the GFPuv gene, the translational stop codons, and the transcriptional terminator was amplified by PCR using forward (5'-GGC GTA TCA CGA GGC CGC GGC CGC TTC ACC TCG AGA-3') and

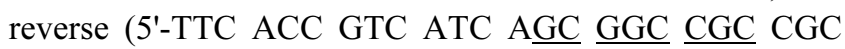
GAG GCA GCT C-3') primers. These primers were designed to produce an amplified fragment containing a Not $\mathrm{I}$ site (underlined) that allowed efficient insertion of the fragment into the transposon delivery vector pBSL299 after digestion with NotI. The PCR conditions comprised incubation at $95^{\circ} \mathrm{C}$ for $9 \mathrm{~min}$ followed by 30 cycles of denaturation at $94^{\circ} \mathrm{C}$ for $1 \mathrm{~min}$ and annealing-extension at $72^{\circ} \mathrm{C}$ for 3 min, with a final extension at $72^{\circ} \mathrm{C}$ for $7 \mathrm{~min}$. The PCR products containing the GFP gene were digested with NotI (all restriction endonucleases were purchased from Takara Bio Inc., Shiga, Japan), purified using a MinElute PCR purification kit (Qiagen K.K., Tokyo, Japan), and inserted into the NotI site of the pBSL299 vector resulting in pBSL299::gfp. This vector was introduced into E. coli MA9 and transformants were isolated on LB agar containing ampicillin $(50 \mu \mathrm{g} / \mathrm{ml})$ and streptomycin $(10 \mu \mathrm{g} / \mathrm{ml})$. Transformants carrying the GFPuv gene were detected by colonyPCR using the uv1f forward (5'-ATG AGT AAA GGA GAA GAA CTT TTC-3') and uv717rl reverse (5'-TTA TTT GTA GAG CTC ATC CAT GC-3') primer set. The PCR conditions comprised incubation at $95^{\circ} \mathrm{C}$ for 9 min followed by 30 cycles of denaturation at $94^{\circ} \mathrm{C}$ for $1 \mathrm{~min}$, annealing at $60^{\circ} \mathrm{C}$ for $1 \mathrm{~min}$, and extension at $72^{\circ} \mathrm{C}$ for $1 \mathrm{~min}$, and a final extension at $72^{\circ} \mathrm{C}$ for $7 \mathrm{~min}$. In addition, we confirmed that the GFP cassette was inserted into pBSL299 by digestion with NotI and SmaI.

The GFP cassette was inserted into the plasmid RK2 in two steps. First, E. coli $\mathrm{C} 600$ and E. coli MA9 underwent triparental mating as donors of RK2 and the vector pBSL299::gfp, respectively, with P. fluorescens RIMD 1615005 as the recipient. Selection on M9 minimal medium plates $^{44)}$, containing $10 \mathrm{mM}$ glucose as the sole carbon source, $30 \mu \mathrm{g} / \mathrm{ml}$ of kanamycin (RK2 marker) and $10 \mu \mathrm{g} / \mathrm{ml}$ of streptomycin (GFP cassette marker) resulted in the isolation of $P$. fluorescens derivatives carrying a GFP cassette inserted into either the chromosome or RK2. Around 1,000 clones were directly visualized by microscopy and those that emitted intense green fluorescence under blue excita- 
tion (450-490 nm) were transferred to fresh M9 minimal medium supplemented with glucose, kanamycin and streptomycin. Clones with the cassette integrated into RK2 were selected from a second mating. Fifteen clones from the first mating were suspended in $1 \mathrm{ml}$ of $0.9 \% \mathrm{NaCl}$ and mated with $P$. putida ATCC 12633. Selection on M9 minimal medium plates supplemented with $10 \mathrm{mM}$ of benzoate as the sole carbon source (which cannot be metabolized by $P$. fluorescens RIMD 1615005), kanamycin $(30 \mu \mathrm{g} / \mathrm{ml})$ and streptomycin $(10 \mu \mathrm{g} / \mathrm{ml})$ resulted in $P$. putida derivatives carrying RK2 with randomly inserted GFP cassettes (GFPtagged RK2 plasmid). Thirty four clones were isolated based on green fluorescence emission under direct microscopic visualization. $P$. putida cells carrying a single plasmid of a size similar to that of untagged RK2 were selected.

\section{Analysis of GFP cassette in RK2 by Southern blotting}

Four P. putida isolates carrying GFP-tagged RK2 plasmids were suspended in $1 \mathrm{ml}$ of $0.9 \% \mathrm{NaCl}$ and mated with spontaneous rifampicin-resistant E. coli W3110. Transconjugants were selected on LB plates supplemented with rifampicin $(150 \mu \mathrm{g} / \mathrm{ml})$, kanamycin $(30 \mu \mathrm{g} / \mathrm{ml})$ and streptomycin $(10 \mu \mathrm{g} / \mathrm{ml})$. E. coli $\mathrm{W} 3110$ cells were confirmed to carry the GFP-tagged RK2 based on emissions of green fluorescence under blue excitation. GFP-tagged RK2 plasmids were prepared using a HiSpeed $^{\mathrm{TM}}$ Plasmid Maxi Kit (Qiagen K.K., Tokyo, Japan) and digested with KpnI and SmaI endonucleases. Double digestion with KpnI and SmaI cut the GFP cassette at one site and the plasmid at nine sites, according to a digestion-based analysis of the Birmingham IncP- $\alpha$ plasmid sequence ${ }^{40}$ (GenBank accession number L27758) performed using freeware pDRAW32 (AnaClone Software, http://www.acaclone.com). Digested plasmids were resolved by electrophoresis in agarose gels and the plasmid DNA was capillary blotted overnight onto hybridization membranes (GeneScreen Plus, NEN ${ }^{\mathrm{TM}}$ Life Science Products, Boston, MA, USA). Fluorescein-labeled probes for detection of the GFP gene on membranes were prepared using ECF Random Prime Labelling (GE Healthcare BioSciences Corp., Piscataway, NJ, USA). Briefly, the GFP gene was amplified by PCR using the primers uv1f and uv717rl, and the products were denatured by heating for 5 min. The DNA was labeled at $37^{\circ} \mathrm{C}$ for $1 \mathrm{~h}$, and nucleotides, primers (random nanomers), denatured DNA, and enzyme (Klenow fragment) were mixed according to the volumes recommended by the manufacturer. The membrane containing plasmid DNA was hybridized with the fluorescein-labeled GFP probe for $16 \mathrm{~h}$ at $60^{\circ} \mathrm{C}$. Thereafter, the membrane was washed twice for $15 \mathrm{~min}$ at $60^{\circ} \mathrm{C}$. The fluorescent signal was amplified using an anti-fluorescein alkaline phosphatase (AP) conjugate and the ECF Signal Amplification System (GE Healthcare Bio-Sciences Corp., Piscataway, NJ, USA) to increase the sensitivity of detecting the GFP gene. In this system, probe-bound AP catalyzes the conversion of the detection reagent into a highly fluorescent product. The GFP gene was finally detected on the membrane by scanning using a Molecular Dynamics FluorImag$\mathrm{er}^{\mathrm{TM}}$ (PMT value 550; $570 \mathrm{~nm}$ filter) (Sunnyvale, CA, USA).

\section{Comparison of transfer frequencies (TFs) of RK2 and $R K 2::$ gfp determined by plate-counting}

We used E. coli W3110 carrying the GFP-tagged RK2 with one insertion, designated RK $2:: g f p$, as donor cells in a preliminary comparison of the TFs against the untagged RK2. The recipient strain was E. coli MA9 which is resistant to chloramphenicol and sensitive to kanamycin. Donors and recipients in the stationary phase from the culture broth were diluted separately in $0.9 \% \mathrm{NaCl}$ at a final concentration of $1 \times 10^{8}$ cells $/ \mathrm{ml}$ (culturability of $10^{7} \mathrm{CFU} / \mathrm{ml}$ on LB agar for both strains). Equal portions taken from these dilutions were mixed at a donor:recipient ratio of $1: 1$ and $30 \mu \mathrm{l}$ aliquots spotted onto cellulose acetate membranes (pore size $0.45 \mu \mathrm{m}$, Advantec Co., Tokyo, Japan) were placed on $\mathrm{LB}$ agar plates and incubated for $16 \mathrm{~h}$ at $37^{\circ} \mathrm{C}$. Membranes carrying mated cells were placed into microtubes containing $1 \mathrm{ml}$ of $0.9 \% \mathrm{NaCl}$ and mixed by voltex to suspend the bacteria. Serial dilutions were spread on LB agar containing chloramphenicol for the enumeration of recipient cells and on LB containing kanamycin and chloramphenicol for that of transconjugants. The plates were incubated for 2 days at $37^{\circ} \mathrm{C}$. All matings proceeded in triplicate and the TFs were compared with those of E. coli W3110 carrying untagged RK2. The TFs were calculated using the equation $T / R$, where $\mathrm{T}$ is the number of transconjugants and $\mathrm{R}$ is the number of recipients.

The second comparison used Pseudomonas species as both donor and recipient. The plasmid RK2::gfp was transferred by biparental mating from E. coli W3110 to P. fluorescens ATCC 13525. Derivatives of $P$. fluorescens carrying RK2::gfp were isolated from M9 minimal medium supplemented with $10 \mathrm{mM}$ of acetate as the sole carbon source, $30 \mu \mathrm{g} / \mathrm{ml}$ of kanamycin and $10 \mu \mathrm{g} / \mathrm{ml}$ of streptomycin. Diluted suspensions of $P$. fluorescens carrying RK2::gfp were mated on membranes with a diluted suspension of $P$. putida at a final concentration $1 \times 10^{8}$ cells $/ \mathrm{ml}($ donor:recipient $=1: 1$ ) (culturability of $0.5-1 \times 10^{7} \mathrm{CFU} / \mathrm{ml}$ on M9 minimal medium supplemented with $10 \mathrm{mM}$ glucose 
for both strains) and incubated for $16 \mathrm{~h}$ at $30^{\circ} \mathrm{C}$. To enumerate recipients and transconjugants, serial dilutions of bacterial suspensions were spread on M9 minimal medium supplemented with benzoate and kanamycin when required. The plates were incubated for 4 days at $30^{\circ} \mathrm{C}$ and the TFs were compared with those of $P$. fluorescens ATCC 13525 carrying untagged RK2. Selective media supplemented with kanamycin and/or tetracycline were also assayed during the selection of transconjugants.

\section{TFs of RK2::gfp determined by FISH-GFP on nutrient-rich medium}

The donor used for quantifying the ratio of $\mathrm{TF}$ to $P$. putida ATCC 12633 by FISH-GFP was $P$. fluorescens ATCC 13525 carrying RK2::gfp. Conjugation proceeded essentially as described above. The mating mixture of donor and recipient ( $30 \mu \mathrm{l}$; donor:recipient, 1:1) was spotted in triplicate onto cellulose acetate membranes that were placed on nutrient-rich medium (LB agar) and incubated for $16 \mathrm{~h}$ at $30^{\circ} \mathrm{C}$. Thereafter, the membranes were placed in microtubes containing $1 \mathrm{ml}$ of $0.9 \% \mathrm{NaCl}$ and mixed by voltex. Suspended bacterial cells were fixed in PBS containing 8\% paraformaldehyde for $4 \mathrm{~h}$. Appropriately diluted fixed cells $(20 \mu \mathrm{l})$ were spotted into the holes of polyester seals attached to gelatin-coated $(0.1 \%$ gelatin [Becton, Dickinson and Company, Sparks, MD, USA]; $0.01 \% \mathrm{KCr}\left[\mathrm{SO}_{2}\right]_{4}$ ) glass slides and vacuum-dried as described by Maruyama et al. ${ }^{33)}$ for the direct enumeration of bacteria. In situ hybridization proceeded as described by Kitaguchi et al. ${ }^{26)}$ with some modifications. Fifty, 70 and finally $100 \%$ ethanol was dropped onto the sample for $3 \mathrm{~min}$ each, and then the glass slides were vacuum-dried and incubated in a humid chamber for $10 \mathrm{~min}$ at $48^{\circ} \mathrm{C}$ before hybridization. Warm hybridization buffer $(30 \mu \mathrm{l} ; 1 \times \mathrm{SSC}$ buffer $[0.15 \mathrm{M} \mathrm{NaCl}$ and 0.015 $\mathrm{M}$ sodium citrate], $0.01 \%$ sodium dodecyl sulfate [SDS] and $0.02 \mathrm{M}$ Tris- $\mathrm{HCl}[\mathrm{pH} 7.5])^{29)}$ containing $1 \mathrm{ng} / \mu \mathrm{l}$ of Cy3labeled $P$. putida-specific probe (5'-TTG CCA GTT TTG GAT GCA GT-3') ${ }^{15)}$ was dropped onto the sample. After hybridization for $2 \mathrm{~h}$ at $48^{\circ} \mathrm{C}$ in the humid chamber, the samples were washed three times with warm washing solution $(0.9 \mathrm{M} \mathrm{NaCl}, 0.01 \%$ SDS and $0.02 \mathrm{M}$ Tris- $\mathrm{HCl}[\mathrm{pH}$ 7.5]) for $15 \mathrm{~min}$ at $48^{\circ} \mathrm{C}$.

Recipients and transconjugants were also enumerated by counting on plates containing selective medium (M9 minimal medium supplemented with benzoate). When transconjugants were enumerated on the plates, the selective medium was supplemented with kanamycin and/or streptomycin as markers on the plasmid RK2::gfp. Epifluorescence microscopy confirmed that colonies were positive for GFP and
TFs were expressed as the number of transconjugants per recipient cell $(\mathrm{T} / \mathrm{R})$.

\section{TFs of RK2::gfp determined by FISH-GFP and DVC-FISH-GFP on nutrient-limited medium}

Conjugation experiments on nutrient-limited medium (M9 minimal medium supplemented with glucose [10 mM] as the sole carbon source) proceeded essentially as described above. Donors and recipients were mixed at a ratio of $1: 1$ and spotted onto cellulose acetate membranes that were placed on nutrient-limited medium and incubated for $24 \mathrm{~h}$ at $30^{\circ} \mathrm{C}$. Mated bacterial suspensions were fixed with $8 \%$ paraformaldehyde and labeled with FISH as described above (FISH-GFP). To increase the sensitivity for detection and identification of mated cells, DVC was applied to increase the rRNA content of target cells before FISH and provide more time for the accumulation, maturation and expression of GFP within transconjugant cells. Nalidixic acid $(40 \mu \mathrm{g} / \mathrm{ml})$ and LB broth (diluted two-fold) were added to bacterial suspensions ${ }^{53)}$ and incubated at $30^{\circ} \mathrm{C}$ for $16 \mathrm{~h}$ in the dark. The bacterial suspensions were then fixed with $8 \%$ paraformaldehyde and attained using the FISH method. Before and after the DVC method, plasmid TFs were quantified by selective plate-counting and fluorescence microscopy.

\section{Microscopy and image analysis}

Samples were directly observed using a Nikon model E400 epifluorescence microscope at a magnification of $\times 1000$, equipped with a mercury lamp $(100 \mathrm{~W})$ as well as B2A and G-2A filters for blue (GFP) and green (Cy3) excitation, respectively. Microscopic images were captured using a CoolSnap color CCD camera (Roper Scientific, Inc., Tucson, AZ, USA). Ten images were captured per sample for counting. Images of the donor, recipient and transconjugant were analyzed using Adobe Photoshop 7.0 (Adobe Systems, Inc., San Jose, CA, USA). Measurements of the relative fluorescence of GFP gene expression before and after application of the DVC method were analyzed using IPlab Scientific Imaging software (Scanalytics, Inc., Rockville, MD, USA).

\section{Results and Discussion}

\section{Construction and analysis of broad-host-range plasmid} tagged with the GFP gene

Use of the vector pBSL299::gfp (mini-Tn5 transposon) and the mating procedure allowed for the isolation of $P$. putida ATCC 12633 carrying derivatives of RK2 with ran- 


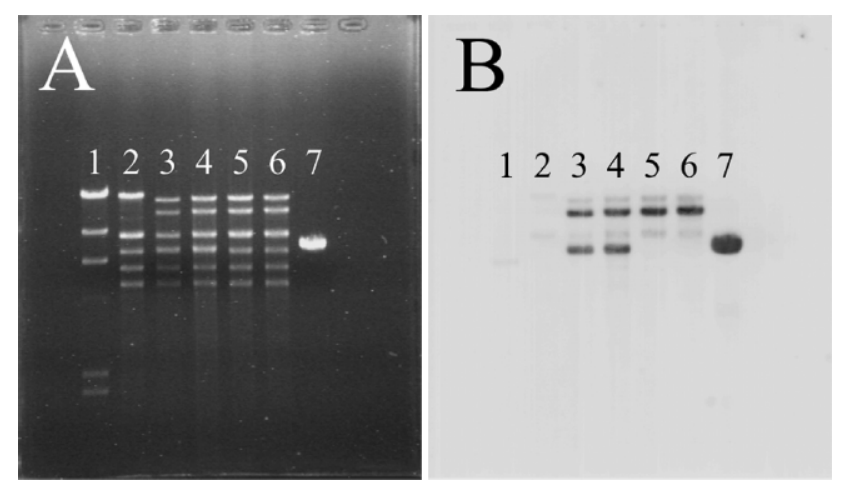

Fig. 1. Analysis of GFP-tagged RK2 plasmids by digestion with endonucleases and Southern blotting. (A) Electrophoretic agarose gel profile after double digestion of GFP-tagged derivatives of RK2 with KpnI and SmaI. (B) Image scanned after Southern blotting using a fluorescent probe to detect the GFPuv gene. 1, DNA marker ( $\lambda$-HindIII digest); 2 , untagged RK2 plasmid (control negative); $3,4,5$ and 6 , GFP-tagged RK2 plasmids; 7, pBSL299::gfp vector (control positive).

domly inserted GFP cassettes. Figure 1A shows double digestion with endonucleases (KpnI and SmaI) of GFP-tagged RK2 plasmid DNA. Electrophoresis on agarose gels revealed different band profiles of GFP-tagged RK2 (Fig. 1A, number 3, 4, 5 and 6) compared with untagged RK2 (Fig. $1 \mathrm{~A}$, number 2). Comparing the profile of untagged RK2 with the profiles of GFP-tagged plasmids, the upper band $(21,412 \mathrm{bp})$ was digested into two smaller bands in all the tagged plasmids. This result suggests that one GFP cassette is inserted into the region between bp 38,682 and 903 of

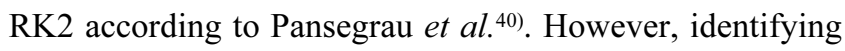
the exact position of the cassette will require further analysis. By using Southern blotting with the GFPuv gene probe, it was possible to determine the number of GFP cassettes inserted into GFP-tagged RK2. The results revealed one insertion in two plasmids (Fig. 1B, number 5 and 6) and two insertions in another two plasmids (Fig. 1B, number 3 and 4). We selected plasmid number 6 with one GFPuv insertion for plasmid transfer experiments and designated it as
$\mathrm{RK} 2:: g f p$.

\section{Comparison of TFs of RK2 and RK2::gfp determined by} plate-counting

Table 2 compares the TFs of RK2 and RK2::gfp using $E$. coli strains. The TFs of RK2::gfp obtained using selective medium supplemented with kanamycin did not significantly differ from ratios observed with untagged RK2, indicating that insertion of the GFP cassette into the plasmid did not affect its transfer mechanism. This observation was confirmed using Pseudomonas strains as donors and recipients of RK2 and RK2::gfp, respectively. Similar TFs were obtained using kanamycin and/or tetracycline as markers on plasmids (data not shown).

Use of the constructed vectors proved to be a rapid and simple way of tagging plasmids with the GFP gene using Pseudomonas and E. coli strains as donors. This type of delivery system has been widely applied to investigation of microbial ecology and the genetic tagging of bacteria ${ }^{4,13,36)}$. All the GFP-tagged plasmids (one or two GFP inserts) achieved a stable and rapid accumulation of GFP protein in donor bacterial strains allowing clear visualization under blue and UV excitation.

\section{Visualization of transconjugant cells by FISH-GFP}

We validated the FISH-GFP method before applying it to transfer experiments, by means of fluorescence in situ hybridization combined with GFP expression applied to an artificial mixture of fixed cells of $P$. fluorescens carrying RK2::gfp, P. putida and P. putida carrying RK2::gfp (Fig. 2). Each bacterium was specifically detected using a combination of images. Figure $2 \mathrm{C}$ shows that the donor is stained green, the recipient red, and the transconjugant yellow, as a consequence of both green and red fluorescence. Similarly, FISH-GFP in the transfer plasmid experiment on nutrientrich medium allowed for the obvious discrimination of transconjugants, donors, and recipient cells (Fig. 2D). The expression of GFP in transconjugant cells was heterogeneous, but the presence of yellow indicated GFP expression

Table 2. Transfer frequencies determined by plate-counting between E. coli and Pseudomonas species carrying RK2 or RK2::gfp plasmids

\begin{tabular}{llll}
\hline \multicolumn{1}{c}{ Donor } & \multicolumn{1}{c}{ Recipient } & Plasmid & TFs $^{\mathrm{a}}\left(10^{-2}\right)$ \\
\hline E. coli $\mathrm{W} 3110$ & E. coli MA9 & RK2 & $5.8 \pm 1.6^{\mathrm{b}}$ \\
& & RK2::gfp & $4.6 \pm 1.0$ \\
P. fluorescens ATCC 13525 & P. putida ATCC 12633 & RK2 & $3.1 \pm 1.2$ \\
& & RK2::gfp & $2.8 \pm 1.7$ \\
\hline
\end{tabular}

\footnotetext{
${ }^{a}$ Transfer frequency was taken as the number of transconjugants per recipient.

${ }^{\mathrm{b}}$ The data represent the means $\pm \mathrm{SE}$ of three independent experiments.
} 

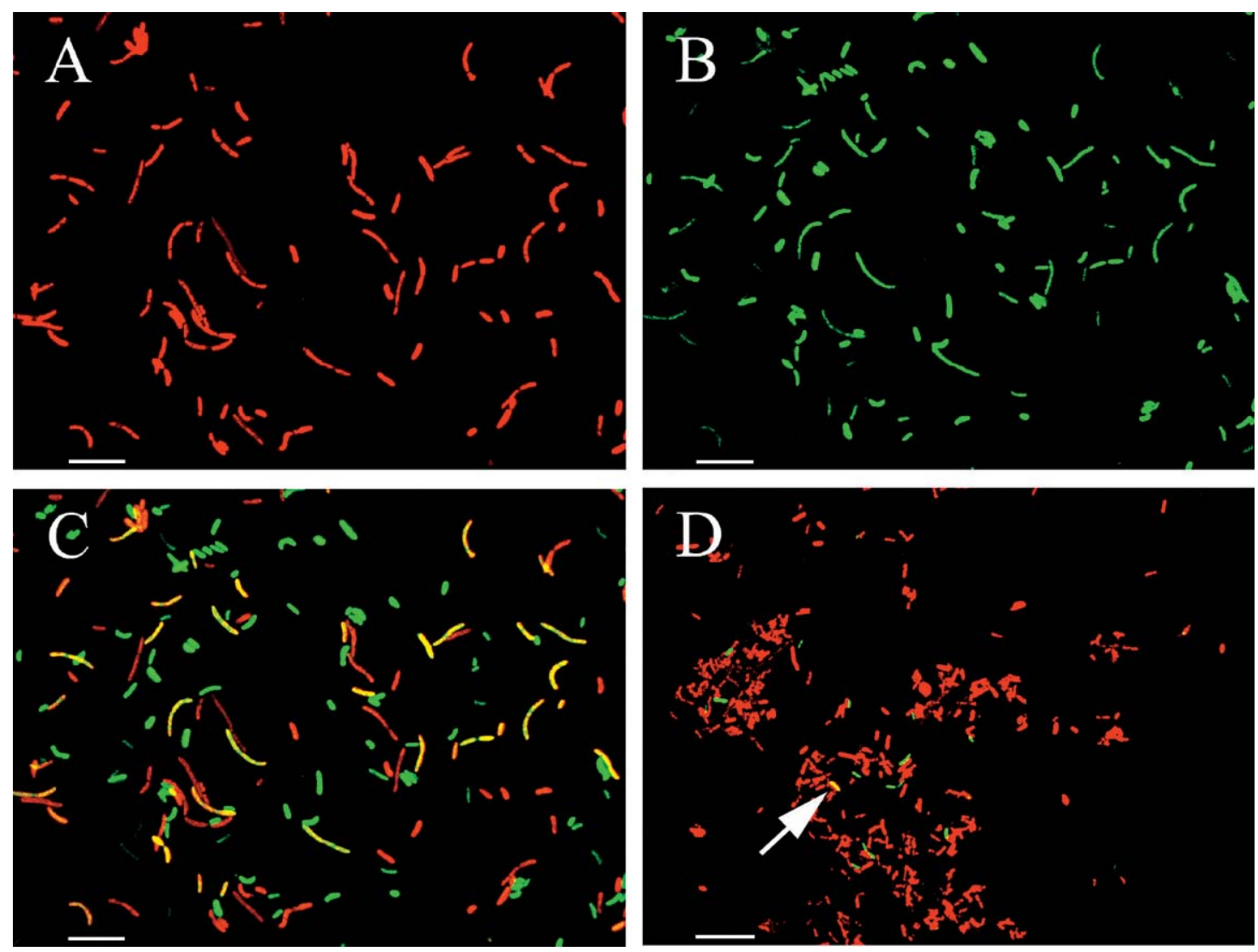

Fig. 2. Discrimination of donor, recipient and transconjugants by using FISH-GFP. (A, B and C) FISH-GFP was applied to an artificial mixture of fixed $P$. fluorescens carrying RK2::gfp, P. putida and P. putida carrying RK2::gfp. (A) P. putida cells emitted red Cy3 fluorescence under green excitation. (B) P. fluorescens and $P$. putida carrying RK2::gfp emitted green fluorescence under blue excitation. (C) Composite image of (A) and (B) showing P. fluorescens carrying RK2::gfp in green, $P$. putida in red and $P$. putida carrying RK2::gfp in yellow. (D) Composite image after conjugation on nutrient-rich medium showing donor ( $P$. fluorescens carrying RK2::gfp; green), recipient ( $P$. putida; red) and transconjugant (P. putida carrying RK2::gfp; yellow, arrow) cells. Bars, $10 \mu \mathrm{m}$.

in those cells. During the conjugation period, recipient cells increased in number more rapidly than donor cells. The lower number of donor cells might be attributed to costs related to the presence of RK2::gfp. It is well documented that plasmid size, plasmid replication, expression of plasmid-encoded genes, and culture conditions confer important physiological or energy costs for a bacterial host, affecting its fitness and competitiveness $\mathrm{s}^{30,31,32)}$.

\section{Observation of transconjugant cells using DVC-FISH-GFP}

On nutrient-limited medium, the use of FISH-GFP and DVC-FISH-GFP also allowed for the discrimination of transconjugants from donor and recipient cells on computer-generated images. However, the growth of donors and recipients was minimal on nutrient-limited as opposed to nutrient-rich medium. Furthermore, the level of GFP was low in most transconjugant cells that appeared orange after the computer images were combined. The DVC method combined with the FISH-GFP approach facilitated the discrimination of transconjugant cells (Fig. 3). The incubation elongated and/or fattened bacterial cells and increased the intensity of the signal from FISH-targeted cells and GFPpositive cells according to the relative fluorescence analyzed using the imaging software IPlab. DVC also resulted in a better accumulation, maturation and expression of GFP within transconjugant cells. Analysis before as opposed to after DVC showed that the total number of GFP-positive cells and TFs did not differ.

\section{Comparison of TFs determined by plate-counting, FISH-GFP and DVC-FISH-GFP}

The plasmid TFs determined by FISH-GFP and DVCFISH-GFP on nutrient-rich and -limited media were higher 

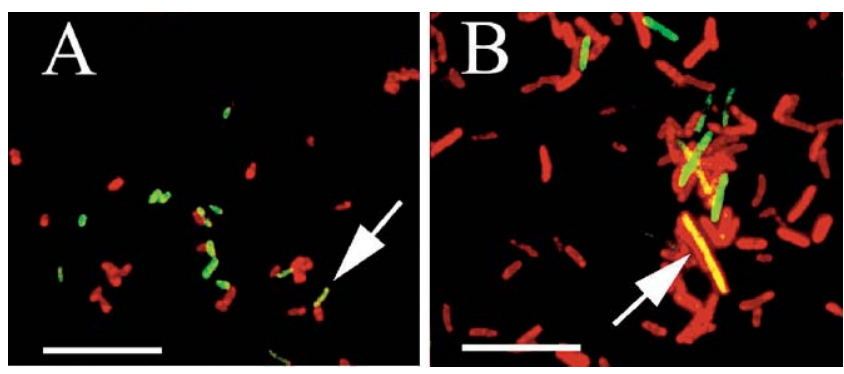

Fig. 3. Detection of transconjugant cells using FISH-GFP (A) and DVC-FISH-GFP (B) after conjugation on nutrient-limited medium. In B, the incubation produced fattened and/or elongated cells and better emissions of fluorescence from GFP within transconjugant cells compared with FISH-GFP alone. Arrows: transconjugant cells. Bars, $10 \mu \mathrm{m}$.

$\left(10^{-1}\right)$ than those obtained by selective plate-counting $\left(10^{-2}\right.$ $-10^{-4}$ ) (Table 3). The values differed significantly depending on the type of antibiotic used as the selection marker in plate counting. O'Morchoe et al. ${ }^{39)}$ observed a similar discrepancy in the number of transconjugants recovered using various antibiotic resistance markers in a study of conjugation in freshwater. Selection with carbenicillin (a penicillin derivative) yielded more transconjugants than that with geneticin (G-418; an aminoglycoside). The difference in recovery might not be due to marker instability, but rather to the specific mechanism of drug resistance, which may not allow sufficient expression of resistance determinants in time for the bacteria to survive exposure to the antibiotic. Differences in the uptake of streptomycin or kanamycin plus streptomycin and/or accumulation of the drugs in recipient cells might also affect the recovery. Reduced uptake of aminoglycosides (kanamycin and streptomycin), mostly in Pseudomonas spp., is likely to be due to membrane permeabilization, but the underlying molecular mechanisms remain unclear ${ }^{3,7)}$. The reduced permeability of the $P$. aeruginosa membrane to streptomycin during bacterial cell growth and the nature of the growth medium obviously af- fected both the incorporation of streptomycin and the minimal inhibitory concentration, resulting in a low level of resistance to streptomycin ${ }^{50)}$.

Although mating on nutrient-limited medium decreased bacterial growth and GFP expression in transconjugants, the transfer rates determined by plate-counting, FISH-GFP and DVC-FISH-GFP were of similar orders of magnitude compared with those on nutrient-rich medium. These observations are consistent with the findings that nutrient limitation does not seriously impede conjugation in natural systems even among starved bacterial cells, and that although a minimum level of activity appeared necessary for plasmid transfer to proceed, transfer rates do not correlate with levels of metabolic activity ${ }^{28,38,45)}$. Interestingly, Hauster and Wuertz $^{23)}$ observed the highest TFs for plasmids under poor nutrient conditions and postulated that the formation of clusters at low concentrations of nutrients during the formation of a biofilm contributes to the high transfer rates under these conditions. The study of Pearce et al. ${ }^{42)}$ showed that TFs were reduced at high nutrient concentrations, suggesting that plasmid transfer is either stimulated when growthlimiting nutrients are scarce or inhibited when they are abundant.

To summarize, the TFs obtained by the FISH-GFP and DVC-FISH-GFP culture-independent approach were 1 to $>3$ orders of magnitude higher than those obtained by determining the number of transconjugants based on CFU. This could be due to the VBNC status of the transconjugants or a loss of plasmids upon cell division even under selective conditions $^{23)}$.

Despite that TFs did not differ significantly between FISH-GFP and DVC-FISH-GFP on nutrient-limited medium, DVC allowed for storage GFP expression within transconjugant cells. The counting of cells became easier; therefore, more transconjugant cells were recorded resulting in higher TFs compared with FISH-GFP alone. Previous reports have showed that the expression from a single copy of the wild-type GFP gene in a chromosome is not strong

Table 3. Transfer frequencies of RK2::gfp plasmids between Pseudomonas species on nutrient-rich and nutrient-limited media determined by plate-counting, FISH-GFP and DVC-FISH-GFP

\begin{tabular}{lcccccc}
\hline \multirow{2}{*}{ Medium } & \multicolumn{3}{c}{ Plate-counting $^{\mathrm{a}}$} & \multirow{2}{*}{ FISH-GFP } & DVC-FISH-GFP \\
\cline { 2 - 4 } & $\mathrm{Km}$ & $\mathrm{Sm}$ & $\mathrm{Km}+\mathrm{Sm}$ & & Not done \\
\cline { 2 - 5 } Rich & $3.8 \pm 2.0 \times 10^{-2} \mathrm{~b}$ & $8.4 \pm 2.8 \times 10^{-4}$ & $2.0 \pm 0.9 \times 10^{-3}$ & & $1.9 \pm 0.2 \times 10^{-1}$ & $1.5 \pm 0.6 \times 10^{-1}$ \\
Limited & $1.7 \pm 0.9 \times 10^{-2}$ & $1.9 \pm 1.1 \times 10^{-4}$ & $1.2 \pm 0.5 \times 10^{-3}$ & & $1.1 \pm 0.3 \times 10^{-1}$ & 1.5 \\
\hline
\end{tabular}

a antibiotics used as a selection marker on the plasmid for the transconjugant on selective media. Km: kanamycin, Sm: streptomycin.

${ }^{\mathrm{b}}$ The data represent the means $\pm \mathrm{SE}$ of three independent experiments. 
enough to be detected by fluorescence microscopy and it has been suggested that approximately 10,000 GFP molecules in the cytoplasm of a cell are necessary for accurate microscopic detection ${ }^{16,41)}$. A new series of GFP mutants have been developed allowing detection of single cells with one copy of the GFP gene in the chromosomes ${ }^{17}$. However, GFP-tagged plasmids show limitations related to i) stability under natural conditions, ii) low sensitivity for single cell detection when there is only a single copy of the GFP gene encoded on the plasmid and a low copy number of plasmids (e.g. large plasmids) within cells, and iii) insufficient time for maturation of GFP within cells under growth-limiting and/or stressful conditions. DVC would provide enough time for GFP molecules to accumulate within bacterial cells and consequently permit a better maturation and expression of GFP resulting in a higher level of detection of transconjugant cells, especially in bacteria with low metabolic activity.

Sørensen et al. ${ }^{47)}$ recently indicated important methodological problems with the study of plasmid transfer in situ. First, conventional methods for detecting plasmid transfer do not distinguish between increased numbers of transfer events and post-transfer selection (clonal expansion of parental cells and transconjugants during long-term conjugation or cultivation). Second, traditional methods produce population-averaged measures of plasmid transfer, which generally do not provide an insight into spatial expansion in non-homogeneous environments. Third, traditional approaches invariably rely on cultivation of donor, recipient and transconjugant populations. DVC combined with FISHGFP could be an useful culture-independent method in studies which require short-term conjugation allowing for a more precise detection of plasmid transfer events, because this method prevents an increase in the number of bacterial cells and post-transfer during mating and DVC. It also provides more time to improve the fluorescence signal level of the transconjugant.

The development of sensitive methods for monitoring conjugative plasmid transfer is of considerable importance in environmental microbiology. Oligotrophic and stressful conditions during conjugation might induce bacterial cells to enter the VBNC state and exhibit low levels of metabolic activity (e.g. insufficient rRNA content detectable by microscopy after FISH and incomplete maturation of GFP protein within cells). Low metabolic activity makes detecting plasmid transfer difficult and the culture-dependent approach underestimates actual transfer frequencies. Investigations into plasmid transfer using culture-independent methods under oligotrophic and stressful conditions are scarce. A recent study using a metal-stressed microcosm revealed plasmid transfer from an $E$. coli strain to a sedimentderived microbial community and long-term plasmid retention in a low-carbon flow ${ }^{46)}$. Conjugal transfer of the plasmid TOL among Pseudomonas under toxic stress has also been studied by Arango Pinedo ${ }^{6}$. Premating exposure to toxicants such as ethanol, toluene and phenol did not result in positive effects on plasmid transfer. However, exposure to sodium-dodecyl-sulfate before mating increased the amount of conjugal TFs, supporting the notion that if plasmid transfer is indeed part of an adaptive response to stress, then stress should increase the ability to release and receive plasmids.

In conclusion, the DVC-FISH-GFP method could be an adequate option for in situ monitoring of conjugative plasmid transfer in laboratory-based experiments and model microcosm, under oligotrophic or stressful conditions where conventional culture methods are difficult to apply, and studies which require short-term conjugation for a precise determination of plasmid transfer rates preventing posttransfer or bacterial growth during mating.

\section{Acknowledgements}

This study was supported in part by a JSPS Grant-in-aid for Scientific Research (A) (no. 15201006). M. Jorquera acknowledges the Mombukagakusho scholarship funded by the Ministry of Education, Science, Sport and Culture, Japan.

\section{References}

1) Alexeyev, M.F., I.N. Shokolenko and T.P. Croughan. 1995. New mini-Tn5 derivatives for insertion mutagenesis and genetic engineering in gram-negative bacteria. Can. J. Microbiol. 41: 10531055 .

2) Amann, R.I., W. Ludwig and K.H. Schleifer. 1995. Phylogenetic identification and in situ detection of individual microbial cells without cultivation. Microbiol. Rev. 59: 143-169.

3) Aminoglycoside Resistance Study Groups. 1994. Resistance to aminoglycoside in Pseudomonas. Trends Microbiol. 2: 347-353.

4) Andersen, J.B., C. Sternberg, L.K. Poulsen, S.P. Bjørn, M. Givskov and S. Molin. 1998. New unstable variants of green fluorescent protein for studies of transient gene expression in bacteria. Appl. Environ. Microbiol. 64: 2240-2246.

5) Arana, I., J.I. Justo, A. Muela, M. Pocino, J. Iriberri and I. Barcina. 1997. Influence of a survival process in a freshwater system upon plasmid transfer between Escherichia coli strain. Microb. Ecol. 33: 41-49.

6) Arango Pinedo, C. and B.F. Smets. 2005. Conjugal TOL transfer from Pseudomonas putida to Pseudomonas aeruginosa: effects of restriction proficiency, toxicant exposure, cell density ratios, and conjugation detection method on observed transfer efficien- 
cies. Appl. Environ. Microbiol. 71: 51-57.

7) Chambers, H.F. and M.A. Sande. 1995. Antimicrobial agents: the aminoglycosides, p. 1103-1121. In J.G. Hardman, L.E. Limbird, P.B. Mollinoff, R.W. Ruddon and A. Goodman Gilman (ed.), The pharmacological basis of therapeutics. McGraw-Hill, New York, N.Y.

8) Christensen, B.B., C. Sternberg, J.B. Andersen, L. Eberl, S. Moller, M. Givskov and S. Molin. 1998. Establishment of new genetic traits in a microbial biofilm community. Appl. Environ. Microbiol. 64: 2247-2255.

9) Crameri, A., E.A. Whitehorn, E. Tate and P.C. Stemmer. 1996. Improved green fluorescent protein by molecular evolution using DNA shuffling. Nat. Biotechnol. 14: 315-319.

10) Dahlberg, C., M. Bergstrom and M. Hermansson. 1998. In situ detection of high levels of horizontal plasmid transfer in marine microbial communities. Appl. Environ. Microbiol. 64: 26702675.

11) Davison, J. 1999. Genetic exchange between bacteria in the environment. Plasmid 42: 73-91.

12) de Lorenzo and K.N. Timmis. 1994. Analysis and construction of stable phenotypes in gram-negative bacteria with Tn5- and Tn10derived minitranposon. Methods Enzymol. 235: 386-405.

13) de Lorenzo, V., M. Herrero, J.M. Sáchez and K.N. Timmis. 1998. Mini-transposon in microbial ecology and environmental biotechnology. FEMS Microbiol. Ecol. 27: 211-224.

14) Dröge, M., A. Pühler and W. Selbitschka. 1999. Horizontal gene transfer among bacteria in terrestrial and aquatic habitats as assessed by microcosm and field studies. Biol. Fertil. Soils 29: 221245.

15) DuTeau, N.M., J.D. Rogers, C.T. Barthomomay and K.F. Reardon. 1998. Species-specific oligonucleotides for enumeration of Pseudomonas putida F1, Burkholderia sp. strain JS150, and Bacillus subtilis ATCC 7003 in biodegradation experiments. Appl. Environ. Microbiol. 64: 4994-4999.

16) Errampalli, D., J.T. Trevors, H. Lee, K. Leung, M. Cassidy, K. Knoke, T. Marwood, K. Shaw, M. Blears and E. Chung. 1997. Bioremediation: A perspective. J. Soil Contam. 6: 207-218.

17) Errampalli, D., K. Leung, M.B. Cassidy, M. Kostrzynska, M. Blears, H. Lee and J.T. Trevors. 1999. Applications of the green fluorescent protein as a molecular marker in environmental microorganisms. J. Microbiol. Methods 35: 187-199.

18) Espinosa-Urgel, M. 2004. Plant-associated Pseudomonas populations: molecular biology, DNA dynamics, and gene transfer. Plasmid 52: 139-150.

19) Geisenberger, O., A. Ammendola, B.B. Christensen, S. Molin, K.H. Schleifer and L. Eberl. 1999. Monitoring the conjugal transfer of plasmid RP4 in activated sludge and in situ identification of transconjugants. FEMS Microbiol. Lett. 174: 9-17.

20) Goodman A.E., E. Hild, K.C. Marshall and M. Hermansson. 1993. Conjugative plasmid transfer between bacteria under simulated marine oligotrophic conditions. Appl. Environ. Microbiol. 59: $1035-1040$.

21) Goodman, A.E., K.C. Marshall and M. Hermansson. 1994. Gene transfer among bacteria under conditions of nutrient depletion in simulated and natural aquatic environments. FEMS Microbiol. Ecol. 15: 55-60.

22) Götz, A., R. Pukall, E. Tietze, R. Prager, H. Tschäpe, J.D. van Elsas and K. Smalla. 1996. Detection and characterization of broad-host-range plasmids in environmental bacteria by PCR. Appl. Environ. Microbiol. 62: 2621-2628.
23) Hausner, M. and S. Wuertz. 1999. High rates of conjugation in bacterial biofilms as determined by quantitative in situ analysis. Appl. Environ. Microbiol. 65: 3710-3713.

24) Kalmbach, S., W. Manz and U. Szewzyk. 1997. Isolation of new bacterial species from drinking water biofilms and proof of their in situ dominance with highly specific $16 \mathrm{~S}$ rRNA probes. Appl. Environ. Microbiol. 63: 4164-4170.

25) Kenzaka, T., N. Yamaguchi, B. Prapagdee, E. Mikami and M. Nasu. 2001. Bacterial community composition and activity in a urban rivers in Thailand and Malaysia. J. Health Sci. 47: 353 361.

26) Kitaguchi, A., N. Yamaguchi and M. Nasu. 2005. Enumeration of respiring Pseudomonas spp. in milk within six hours by fluorescence in situ hybridization following formazan reduction. Appl. Environ. Microbiol. 71: 2748-2752.

27) Kogure, K., U. Simidu and N. Taga. 1979. A tentative direct microscopic method for counting living marine bacteria. Can. J. Microbiol. 25: 415-420.

28) Kroer, N., T. Barkay, S. Sørensen and D. Weber. 1998. Effect of root exudates and bacterial metabolic activity on conjugal gene transfer in the rhizosphere of a marsh plant. FEMS Microbiol. Ecol. 25: 375-384.

29) Lemke, M.J., C.J. McNamara and L.G. Leff. 1997. Comparison of methods for the concentration of bacterioplankton for in situ hybridization. J. Microbiol. Methods 29: 23-29.

30) Lilley, A.K. and M.J. Bailey. 1997. Impact of plasmid pQBR103 acquisition and carriage on the phytosphere fitness of Pseudomonas fluorescens SBW25: burden and benefit. Appl. Environ. Microbiol. 63: 1584-1587.

31) Lilley, A.K., M.J. Bailey, M. Barr, K. Kilshaw, T.M. TimmisWilson, M.J. Day, S.J. Norris, T.H. Jones and H.C. Godfray. 2003. Population dynamics and gene transfer in genetically modified bacteria in a model microcosm. Mol Ecol. 12: 3097-3107.

32) Lugtenberg, B.J.J., L.L. Dekkers and G.V. Bloemberg. 2001. Molecular determinants of rhizosphere colonization by Pseudomonas. Annu. Rev. Phytopathol. 39: 461-490.

33) Maruyama, F., N. Yamaguchi, T. Kenzaka, K. Tani and M. Nasu. 2004. Simplified sample preparation using frame spotting method for direct counting of total bacteria by fluorescence microscopy. J. Microbiol. Methods 59: 427-431.

34) Moter, A. and U.B. Gobel. 2000. Fluorescence in situ hybridization (FISH) for direct visualization of microorganisms. J. Microbiol. Methods 41: 85-112.

35) Muela, A., M. Pocino, I. Arana, J.I. Justo, J. Irreberri and I. Barcina. 1994. Effect of growth phase and parental cell survival in river water on plasmid transfer between Escherichia coli strains. Appl. Environ. Microbiol. 60: 4273-4278.

36) Nancharaiah, Y.V., P. Wattiau, S. Wuertz, S. Bathe, S.V. Mohan, P.A. Wilderer and M. Hausner. 2003. Dual labeling of Pseudomonas putida with fluorescent proteins for in situ monitoring of conjugal transfer of the TOL plasmid. Appl. Environ. Microbiol. 69: 4846-4852.

37) Nishimura, M., K. Kita-Tsukamoto and K. Kogure. 1993. A new method to detect viable bacteria in natural seawater using $16 \mathrm{~S}$ rRNA oligonucleotide probe. J. Oceanogr. 49: 51-56.

38) Normander, B., B.B. Christensen, S. Molin and N. Kroer. 1998. Effect of bacterial distribution and activity on conjugal gene transfer on the phylloplane of the bush bean (Phaseolus vulgaris). Appl. Environ. Microbiol. 64: 1902-1909.

39) O'Morchoe, S.B., O. Ogunseitan, G.S. Sayler and R.V. Miller. 
1988. Conjugal transfer of R68.45 and FP5 between Pseudomonas aeruginosa strains in a freshwater environment. Appl. Environ. Microbiol. 54: 1923-1929.

40) Pansegrau, W., E. Lanka, P.T. Barth, D.H. Figurski, D.G. Guiney, D. Haas, D.R. Helinski, H. Schwab, V.A. Stanisich and C.M. Thomas. 1994. Complete nucleotide sequence of Birmingham Inc $\alpha$ plasmids: compilation and comparative analysis. J. Mol. Biol. 239: 623-663.

41) Patterson, G.H., S.M. Knobel, W.D. Sharif, S.R. Kain and D.W. Piston. 1997. Use of the green fluorescent protein and its mutants in quantitative fluorescence microscopy. Biophys J. 73: 27822790.

42) Pearce, D.A., M.J. Bazin and J.M. Lynch. 2000. Substrate concentration and plasmid transfer frequency between bacteria in a model rhizosphere. Microb. Ecol. 40: 57-63.

43) Rodenacker, K., A. Brühl, M. Hausner, M. Kühn, V. Liebscher, M. Wagner, G. Winkler and S. Wuertz. 2000. Quantification of biofilms in multispectral digital volumes from confocal laser scanning microscopes. Image Anal. Stereol. 19: 151-156.

44) Sambrook, J., E.F. Fritsch and T. Maniatis. 1989. Molecular cloning: a laboratory manual, 2nd ed. Cold Spring Harbor Laboratory, Cold Spring Harbor, N.Y.

45) Schwaner, N.E. and N. Kroer. 2001. Effect of plant species on the kinetics of conjugal transfer in the rhizosphere and relation to bacterial metabolic activity. Microb. Ecol. 42: 458-465.
46) Smets, B.F., J.B. Morrow and C.P. Arango. 2003. Plasmid introduction in metal-stressed subsurface-derived microcosms: plasmid fate and community response. Appl. Environ. Microbiol. 69: 4087-4097.

47) Sørensen, S.J., M. Barley, L.H. Hansen, N. Kroer and S. Wuertz. 2005. Studying plasmid horizontal transfer in situ: a critical review. Nat. Rev. Microbiol. 3: 700-710.

48) Spiers, A.J., A. Buckling and P.B. Rainey. The cause of Pseudomonas diversity. Microbiology 146: 2345-2350.

49) Timmis, K.N. 2002. Pseudomonas putida: a cosmopolitan opportunist par excellence. Environ. Microbiol. 4: 779-781.

50) Tseng, J.T., L.E. Bryan and H.M. Van Den Elzen. 1972. Mechanisms and spectrum of streptomycin resistance in a natural population of Pseudomonas aeruginosa. Antimicrob. Agents Chemother. 2: 136-141.

51) van Elsas, J.D., J. Fry, P. Hirsch and S. Molin. 2000. Ecology of plasmid transfer and spread, p. 175-206. In C.M. Thomas (ed.), The horizontal gene pool. Harwood Academic Publishers, Amsterdam, The Netherlands.

52) van Elsas, J.D. and M.J. Bailey. 2002. The ecology of transfer of mobile genetic elements. FEMS Microbiol. Ecol. 42: 187-198.

53) Yokomaku, D., N. Yamaguchi and M. Nasu. 2000. Improved direct viable count procedure for quantitative estimation of bacterial viability in freshwater environments. Appl. Environ. Microbiol. 66: $5544-5548$. 